\title{
Design of Online Vocal Music Course Based on Azure-PaaS Platform
}

\author{
https://doi.org/10.3991/ijet.v12.i09.7495 \\ Zhuo Li \\ University of Science and Technology Liaoning, Anshan, Liaoning \\ $15042251746 @ 163 . \mathrm{com}$
}

\begin{abstract}
With the development of Web service of internet technology, more and more teaching functions can be achieved through network. The emergence of online courses adapts to the development trend of internet, and has become a new teaching model. We applied a WIFI-based intelligent PPT technology innovatively combined with Azure-PaaS cloud computing technology, and designed a new type of online course in the aspects of overall structure and teaching function (the realization of online course is established from 3 aspects: learning module, communication module and evaluation module) according to the cognitive assimilation theory, and then analyzed the teaching effect of the university online vocal music course based on Azure-PaaS platform. Results demonstrate that $47.7 \%$ of students used this online course platform frequently and $27.3 \%$ of students logged in this platform for learning very frequently. These findings indicate the teaching effect of internet-based vocal music course can be improved, and can provide reference for the design of vocal music web courses in Universities.
\end{abstract}

Keywords-Online education, cloud computing, teaching effect, Azure-PaaS, vocal music course

\section{Introduction}

In the era of big data, favorable resources and environment help the establishment and operation of network platform [1]. The computer has more and more functions, so relevant demonstration and teaching tasks can be finished on the computer. At present, teaching courses through multimedia system has become the main way of classroom teaching in schools. Multimedia teaching can enrich the teaching forms of the whole lesson greatly, and the rich manifestation forms can improve students' interest and understanding level of corresponding knowledge. Meanwhile, teachers can make good use of multimedia technology to control the teaching pace, improve the teaching effect, etc. All above teaching tasks conducted through multimedia technology on the spot are usually called single offline teaching [2]. With the development of Web service of internet technology, more and more teaching functions can be achieved through network. Therefore, the emergence of online courses adapts to the development trend of internet well, and has become a new teaching model. Online courses 
mean "all course contents of a subject and teaching activities expressed through network, including two parts: the course contents organized according to definite teaching objectives and teaching strategies and the supporting environment for online teaching" [3]. Online music education course is a brand-new music education system integrated of the multimedia information technology and the traditional music education. The vocal music course is a branch of music education, which is the professional basic course of musicology for teachers. In order to meet students' needs on diverse learning and the mass of course resources, the vocal music teaching needs to be reformed urgently, and the cloud computing technology proposed in the internet field recently can effectively conform to the online teaching characteristics of university vocal music courses [4]. The organic combination of cloud computing technology and online vocal music course education for the establishment of modernized courses supported by internet and other education information technologies can fully play the role of "network cloud" of the cloud computing technology, and effectively improve the information management function of multimedia resources of whole online vocal music course teaching.

\section{State of the art}

With the rapid development of internet, the demand for online education is higher and higher. Not only in primary and secondary school classrooms, but also in American universities, online teaching has been adopted. MOOC online course is a form of American new-type education reform [5], such as Coursera, Edx, and Udacity [6]. The latest survey results show that, in America, the number of people learning online on corresponding websites has increased by more than $200 \%$ and the employees from nearly $60 \%$ of enterprises has trained by online form. At present, almost all universities have started the online course teaching mode, and there are $72 \%$ of universities can award corresponding degrees or Diplomas to students by internet [6]. Since 1996, the German government and telecom companies have invested DEM 68 million jointly in the teaching and training of computer basics in Germany, and some other German large enterprises jointly have invested DEM 500 million together in support, so that internal network can be accessed in all schools and every family has a computer [7].

In China, the combination of university education and excellent foreign online education platform has become the development trend of online course education. For example, Peking University and Tsinghua University carried out corresponding cooperation with Edx to launch the MOOC platform [8], and Fudan University and Shanghai Jiaotong University cooperated with Coursera to develop the MOOC platform suitable for the Chinese university education [9]. Meanwhile, in China, there are more and more new online course designs, especially the designs and researches on the different types of online courses. Yang [10] pointed that, in the current technical environment of new media, the online art courses in universities at present must be designed from the perspective of the development of whole culture industry. $\mathrm{Su}$ et al. [11] from Jinan University proposed that, the role of online learning platform was to 
combine the education process of online course with the learning process organically, so as to completely play the role of students' initiative in online learning and broaden the function of online learning.. Zhang [12] chose the course of medical information retrieval as the research object to analyze the advantages and disadvantages of rising multimedia teaching methods with the online course as main mode and put forward some suggestions on how to carry forward the advantages and avoid the disadvantages of the corresponding online courses.

With the rapid development in the information era, we need higher and higher demand for new teaching methods for online vocal music courses. However, there are some deficiencies in the application of online courses. Firstly, the current online vocal music courses are applied with multimedia technology generally and the multimedia platforms in some classrooms are not really connected with internet, which prevents teachers from expanding knowledge in class. Secondly, when teachers are conducting the online vocal music courses by PPT, they need to be equipped with a voice power amplifier for the collection and amplification of voice signals. The common voice devices have limited moving ranges, voice output power and coverage area and ordinary tone quality. For these deficiencies, we explored and researched a new-type designing scheme of university online vocal music course through the Azure cloud service platform supplied by Microsoft for the vocal music course in art courses in order to improve the resource sharing capability of whole online vocal music course. Meanwhile, we suggested trying the mobile teaching platform in the university online vocal music courses for the first time. For the convenience of the teaching of whole vocal music course, we used a type of WIFI-based intelligent PPT with the function of microphone and courseware page turning in the teaching process of this online course to provide reference for the online vocal music course teaching.

\section{Theoretical construction}

\subsection{PaaS cloud computing platform}

PaaS cloud computing platform can realize the information sharing in whole data transmission process effectively with the function of rapid deployment. The advantages of the cloud computing platform are to effectively simplify the form of sharing information resources and improve the efficiency of sharing information resources. The main framework, $\mathrm{M}-\mathrm{V}-\mathrm{C}$, runs through the whole PaaS cloud computing platform, which is composed of three parts: model payer, display layer and operation layer (as shown in Figure 1). During the cloud computing process of whole PaaS platform, the user shall initiate a corresponding user request at first, and then this request will be transmitted to the information dispatcher, which is used to decide which part to process this request. 


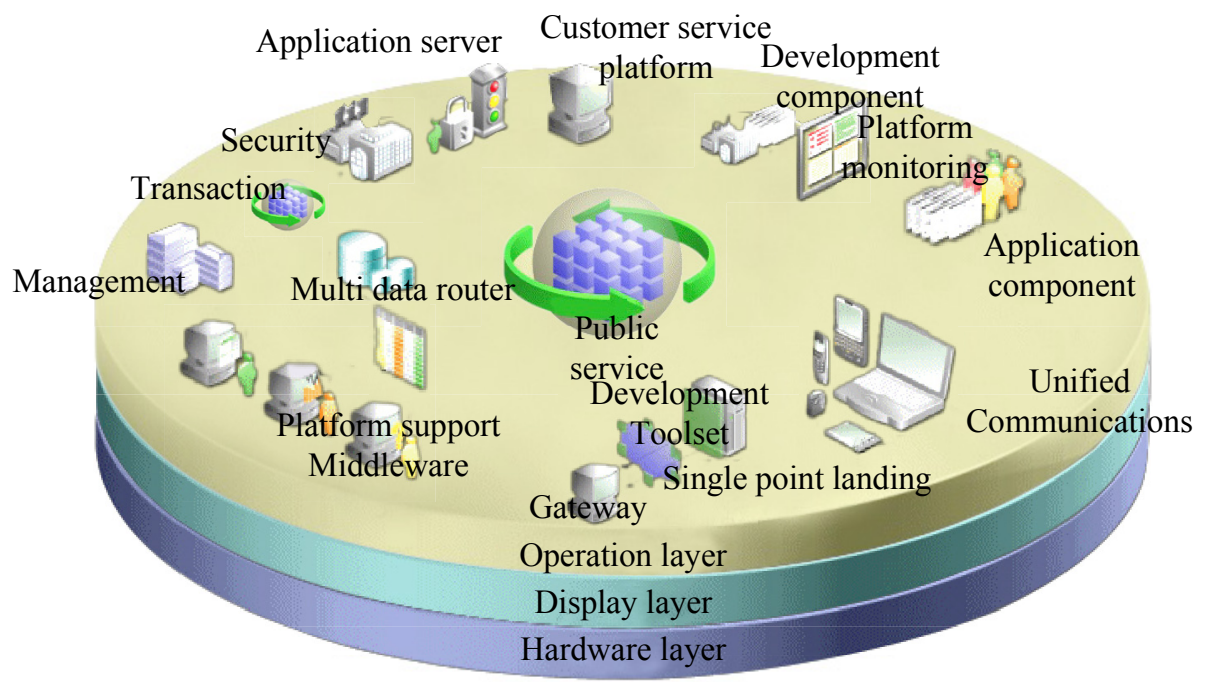

Fig. 1. PaaS platform architecture

Model layer: the main function of this layer is to process the information exchange in whole computation structure and transmit all underlying data at the same time, screen the corresponding data in the whole data transmission process by rule, and get rid of underlying information that is not suitable for the whole computation rule.

Display layer: in the whole displaying course, the following formulas (1) and (2) will be used to accurately orientate the picture displayed.

$$
\begin{aligned}
& x^{\prime}=x \cos \theta-y \sin \theta \\
& y^{\prime}=y \cos \theta+x \sin \theta
\end{aligned}
$$

Operation layer: its main function is to process the whole data information and coordinate the operation and data transmission of whole PaaS platform.

\subsection{Theoretical support for cognitive assimilation}

The most important factor to influence a student's learning is his or her existing cognitive structure. The theory of cognitive assimilation emphasizes that the student's learning shall be the significant reception learning, which is conducted through the interaction between the new knowledge and the relevant concept in the student's cognitive structure, and its result is the meaning assimilation of old knowledge and new knowledge. For example, when students are learning the chapter of voice training and singing practice, the teacher shall explain them and assign task in advance so that students can understand the contents to be learned. Meanwhile, the teacher shall display other related audio workstations and the knowledge points of audio processing software in the extracurricular material links of the online platform, so that students will think of the existing knowledge frame in mind and further understand these sim- 
ple extracurricular materials when browsing these links even if students don't have any knowledge or experience. Thus, it is easier for teachers to master and be familiar with these knowledge points in class. The concept map of cognitive assimilation is as shown in Figure 2.

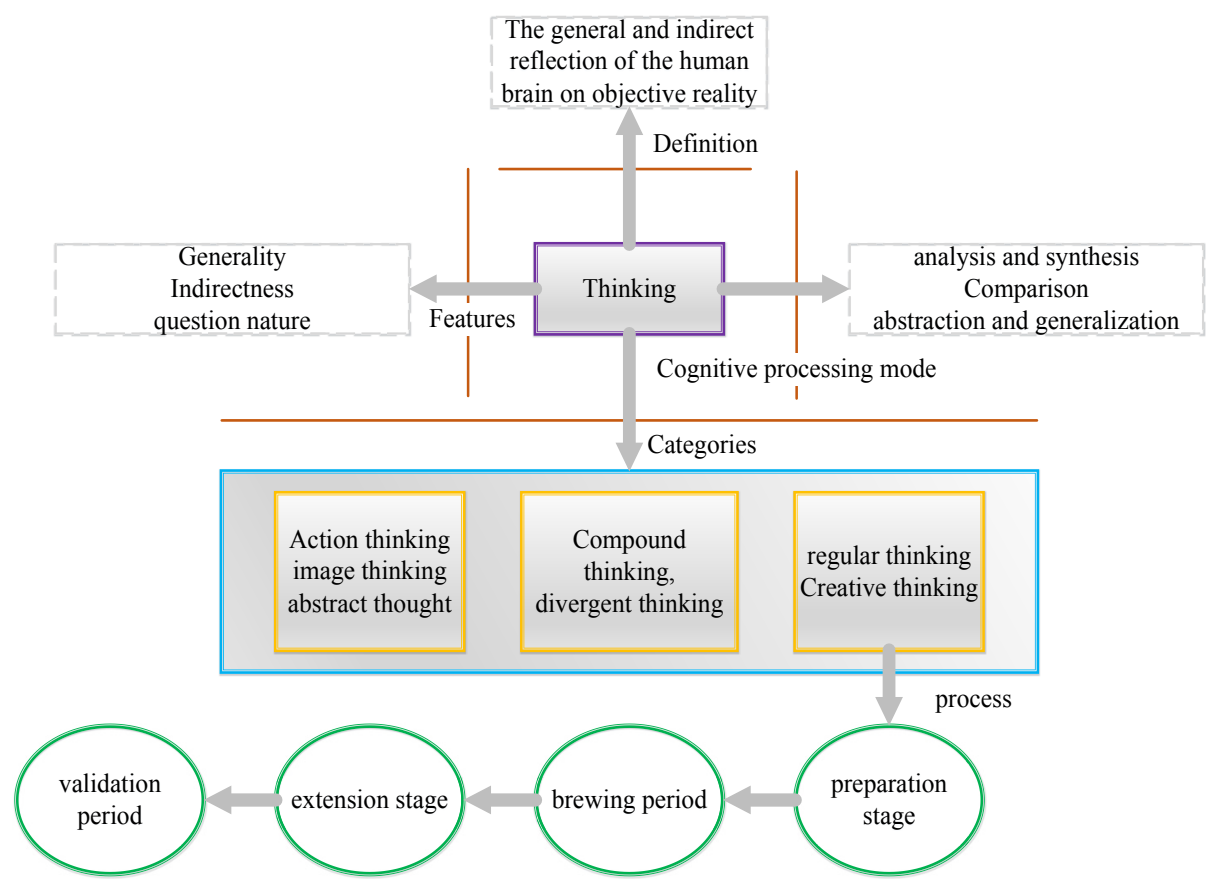

Fig. 2. Concept map of cognitive assimilation

\subsection{WIFI-based intelligent PPT technology}

The WIFI-based intelligent PPT technology means that the telecontrol system of the technology has intelligent behavior. For example, the computer user can turn the pages of courseware through pressing the buttons on the remote control when he is not beside the computer, and the telecontrol system has corresponding microphone, which can collect the courseware presenter's voice to be amplified and output on the computer in the process of displaying corresponding content. This system is mainly equipped with the single chip microcomputer (SCM) and exchanges corresponding information with the computer through the WIFI module connected with SCM. The general framework of the WIFI-based intelligent PPT technology is as shown in Figure 3 . 


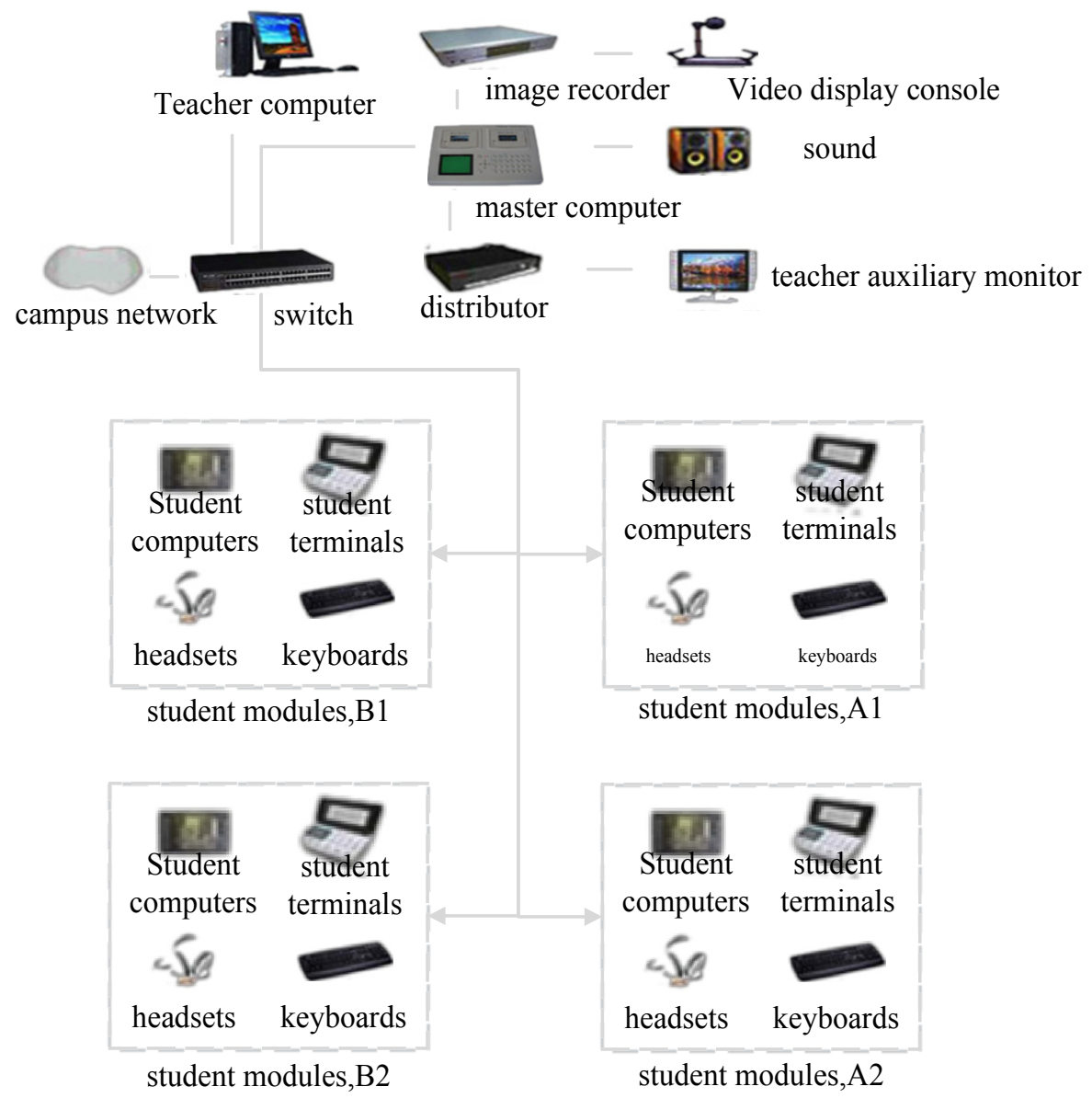

Fig. 3. The general framework of the WIFI-based intelligent PPT technology

\section{The Design of Online Vocal Music Course Based on Azure- PaaS Platform}

\subsection{Overall structure of online course}

The overall structure of this vocal music online course is shown in Figure 4, including three parts: user interface layer, logic control layer and data exchange layer. Figure 4 is the basic design drawing of the university online vocal music course based on Azure-PaaS platform. 


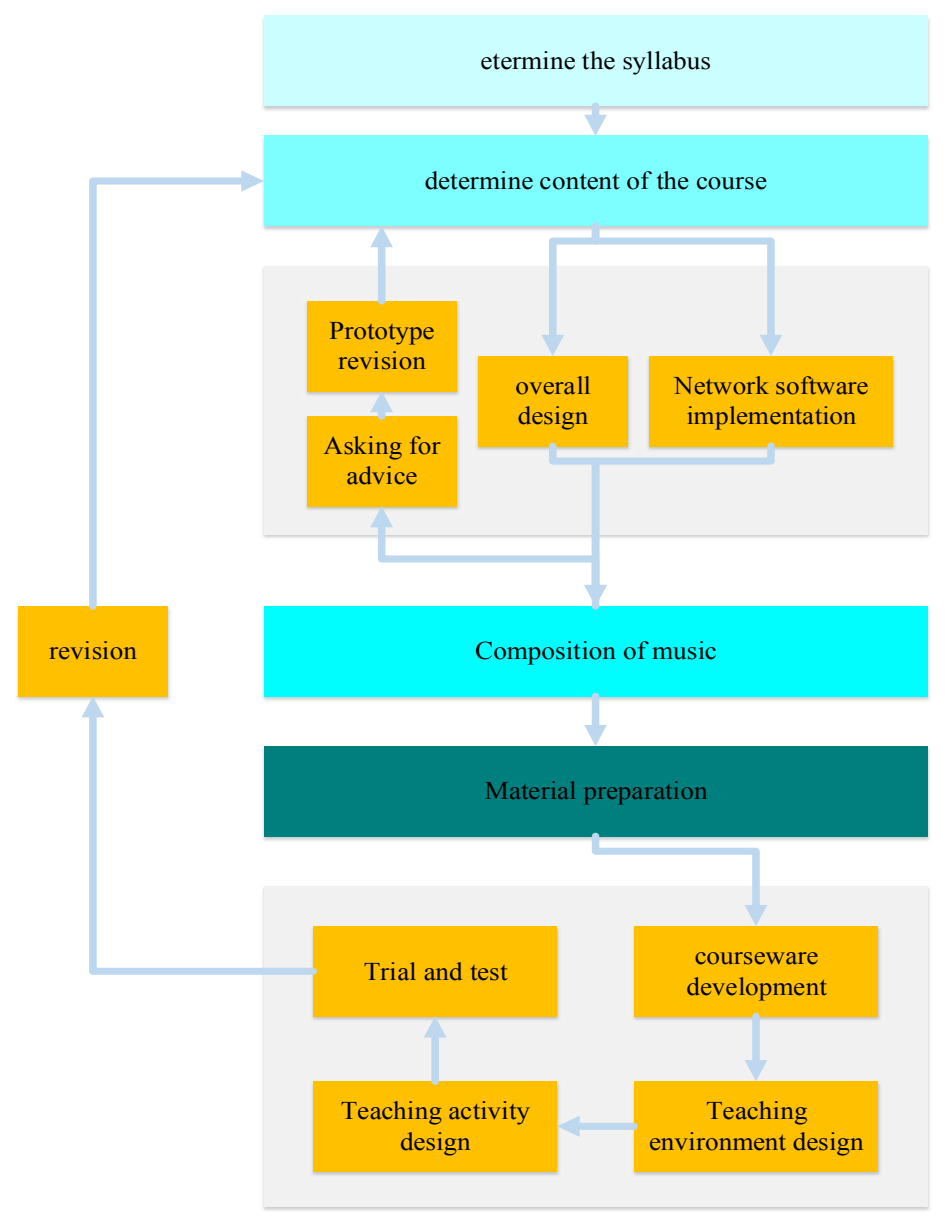

Fig. 4. The basic design drawing of the university online vocal music course based on AzurePaaS platform

\subsection{Realization of teaching function of online course}

The teaching function design of the university online vocal music course based on Azure-PaaS platform overcomes the feature of simplification of traditional online teaching mode. The whole teaching function design contains three basic modules: learning module, communication module and evaluation module.

Learning module. The main feature of the learning module of this online vocal music course is student-centered so that students can fully learn about related information of the course, homework content and the multimedia information resources shared in class when learning.

Course information. The content in this part of the learning module is the course introduction and some other summary materials, including the course objective, teaching scheme, course arrangement, experimental arrangement, etc. 
Resource sharing. This is the most important part in whole online course teaching. Teachers can upload related multimedia resources according to their own class lesson content, and at the same time, the space occupied by the multimedia resources uploaded can be saved sequentially in this resource sharing region combined with Azure-PaaS platform. Students can download relevant multimedia resources and classroom courseware according to their own interests, so that they can not only make obtain corresponding resources more conveniently, but also they can gain new knowledge by reviewing old and improve their interests in learning.

Homework information. This online vocal music course also includes releasing homework information, uploading students' homework and teachers' correcting homework online. Before the deadline of uploading homework, students can upload the homework at any time, and teachers can correct the homework online at any time. Meanwhile, students can upload related multimedia audio and video homework through this platform and this platform can inspect students' learning comprehensively.

Communication module. There is a discussion board on this online course platform where teachers and students can discuss the issues about learning sufficiently. If students encounter the questions they don't understand in class, they can ask them in the discussion board, and other students can express their views on these questions, and teachers can make corresponding analysis.

Evaluation module. The evaluation module of this online course takes good account of students' comprehensive performance in the whole learning process. Students' frequency of logging in the online course platform, online duration, liveness in the discussion board, homework completeness, frequency of watching the learning resources and so on are the indexes to evaluate students' learning of this online vocal music course. The training room of the online vocal music course is shown in Figure 5 and the students' internship and practical training of the online vocal music course is shown in Figure 6.

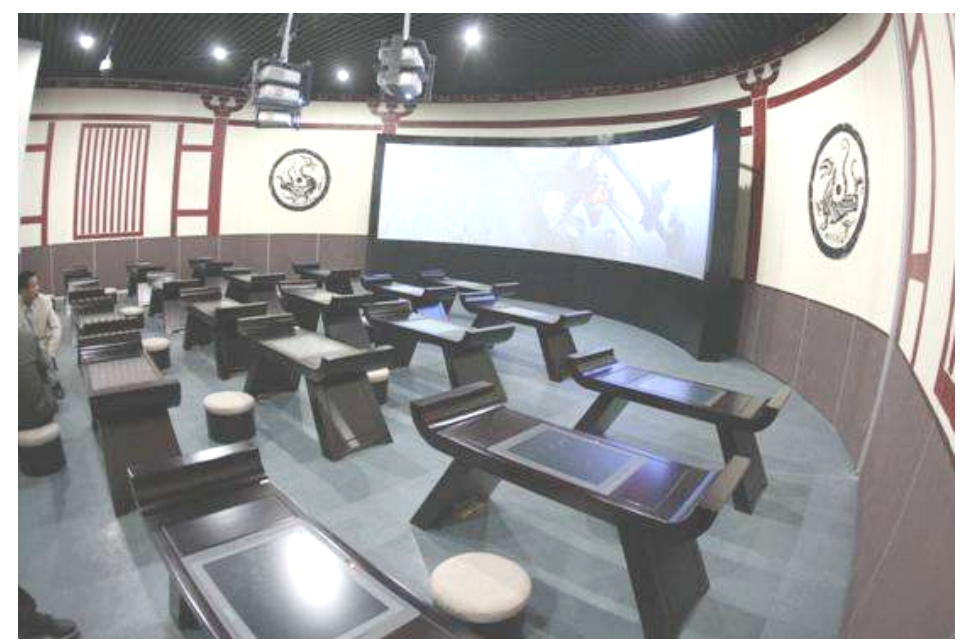

Fig. 5. The training room of the online vocal music course 


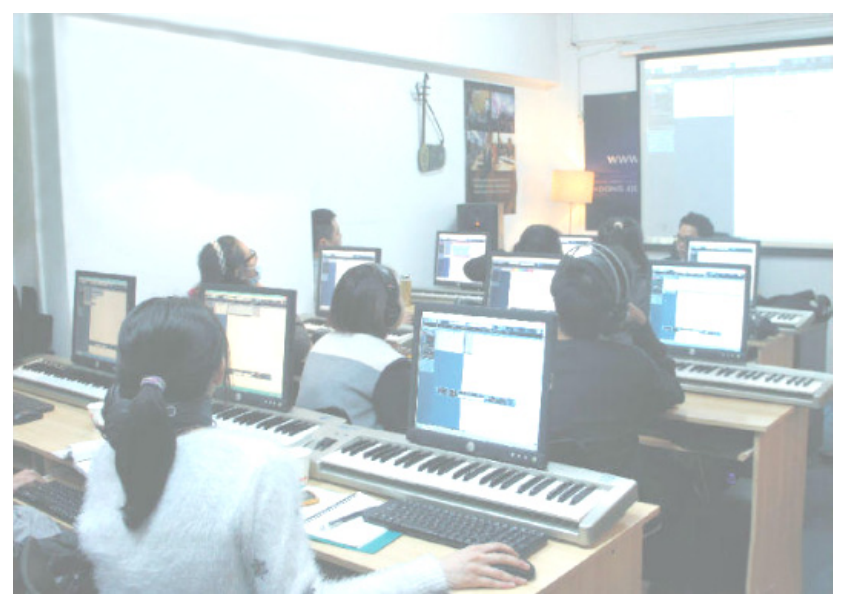

Fig. 6. The students' internship and practical training of the online vocal music course

\subsection{Effect check}

After stating the teaching function and basic structure of the university online vocal music course based on Azure-PaaS platform, we conducted a teaching experiment to the teaching effect of the platform in a university in China, surveyed 179 students' learning of this course, understood their learning through this online platform, and analyzed the advantages and disadvantages of the using effect.

In this article, we surveyed and analyzed the students' use duration and frequency of this platform at first, and the survey results are shown in Table 1.

It was discovered that in the survey results of students' use frequencies, $27.3 \%$ of students logged in this platform for learning very frequently, and their use frequencies of this online course platform were high. However, after deep communication with them, we discovered that their use duration of this platform was within 20 minutes. $47.7 \%$ of students used this online course platform frequently, but their use duration every time was from 20 minutes to 40 minutes compared the students with very high frequencies. $15.3 \%$ of students used the platform with common frequencies, because their only purpose was to complete the corresponding homework assigned by teachers. $6.8 \%$ of students didn't use the online platform for corresponding learning frequently, and the main reason was that they were not interested in learning and had low learning enthusiasm. Meanwhile, it was not compulsory for students to learn on this online course platform, which caused them not to use the platform.

In order to judge the influence of the online vocal music course on students' learning effect, we made a corresponding survey in this article. After survey, 179 students thought that the influence of the online vocal music course on the learning effect in many aspects as shown in Table 2 .

$5.2 \%$ of students though they still didn't adapt to learning the online vocal music course and they were more suitable for the traditional online education methods, and the new-type online course education model didn't improve their learning effect; $59.7 \%$ of students thought that the principal factor in the learning process of the 
Table 1. Use frequency of the online vocal music course platform

\begin{tabular}{|l|c|c|c|c|}
\hline \multicolumn{1}{|c|}{ Use frequency } & Very high & High & Common & Low \\
\hline Number & 49 & 84 & 27 & 19 \\
\hline Proportion & $27.3 \%$ & $47.7 \%$ & $15.3 \%$ & $9.7 \%$ \\
\hline
\end{tabular}

Table 2. The factor influencing the learning effect of online course

\begin{tabular}{|l|c|c|c|c|c|}
\hline $\begin{array}{c}\text { Influence } \\
\text { factor }\end{array}$ & $\begin{array}{c}\text { Not adapt to } \\
\text { online leaning }\end{array}$ & $\begin{array}{c}\text { Student's con- } \\
\text { sciousness }\end{array}$ & $\begin{array}{c}\text { Teachers' } \\
\text { attention }\end{array}$ & $\begin{array}{c}\text { Platform } \\
\text { stability }\end{array}$ & $\begin{array}{c}\text { Insufficient discus- } \\
\text { sion and communi- } \\
\text { cation }\end{array}$ \\
\hline Number & 9 & 107 & 135 & 46 & 108 \\
\hline Proportion & $5.2 \%$ & $59.7 \%$ & $75.6 \%$ & $25.7 \%$ & $61.3 \%$ \\
\hline
\end{tabular}

online course lied in the students themselves, and their self-consciousness in learning the online course was the most important factor influencing the students' learning effect. $75.6 \%$ of students thought that teachers' conscientiousness of corresponding courses in the learning process influenced their learning effect greatly. If teachers didn't pay much attention to the whole online platform, didn't update the course resources frequently, or didn't actively participate in the discussions with students or answer questions discussion board, students' learning effect in the whole platform was not ideal. $25.7 \%$ of students thought that the stability of the online course platform influenced their learning effect, but because sometimes the online course platform couldn't be accessed and the multimedia resources crashed, students' learning efficiency was reduced and the feedback of learning effect was not obvious. $61.3 \%$ of students thought that their learning questions and difficulties encountered in the online course were not replied or discussed in time in the discussion board after they sought helps, which also influenced their learning effect of the online course to some extent.

\section{Conclusions}

We designed and realized the university online vocal music course based on Azure-PaaS platform, tried the application of the WIFI-based intelligent PPT technology, established the overall structure of the university online vocal music course based on Azure-PaaS platform. Meanwhile, we explored new-type teaching models and methods for the online course teaching, and tested and analyzed the teaching effect of the university online vocal music course based on Azure-PaaS platform. The resulted showed that the WIFI-based intelligent PPT technology was used conveniently for teaching and could improve the vocal music course teaching. However, this technology was applied only in small region temporarily and needed to be further popularized. In a word, the internet-based online vocal music course can improve the teaching effect, but it still needs to be improved in some aspects after survey. However, with the rapid development of the current information era, all above problems can be solved effectively, so to learn online courses based on various internet technologies has become a general trend. After deep research and overcoming the existing problems, 
the whole online course teaching will become larger in scale and more dynamic. This research provides reliable reference and objective evaluation for the development of online courses.

\section{References}

[1] Barranco, M., Proenza, J., Almeida, L. The development of a robust, autonomous sensor network platform for environmental monitoring. Iop Sensors \& Their Applications University of, 2003, vol. s117-118(3), pp. 112-120.

[2] Akbulut, E. Levels of Materializing the Purpose in Music Education Lecture in the Programme of Pre-School Department of Educatiom Faculty. Pamukkale Üniversitesi Sosyal Bilimler Enstitüsü Dergisi 2013, vol. 14, pp. 9-16.

[3] Martins, L.L., Kellermanns, F.W. A Model of Business School Students' Acceptance of a Web-Based Course Management System. Academy of Management Learning \& Education, 2004, vol. 3(1), pp. 7-26. https://doi.org/10.5465/AMLE.2004.12436815

[4] Unal, Z., Unal, A. Evaluating and Comparing the Usability of Web-Based Course Management Systems. Journal of Information Technology Education, 2011, vol. 10, pp. 19-38.

[5] Robinson, A.C., Kerski, J., Long, E.C., et al. Maps and the geospatial revolution: teaching a massive open online course (mooc) in geography. Journal of Geography in Higher Education, 2015, vol. 39(1), pp. 65-82. https://doi.org/10.1080/03098265.2014.996850

[6] Mou, Z.S., Dong, B.J. Exploration of Blended Learning Mode Based on MOOCTaking Coursera Platform for Example, Modern Educational Technology, 2014, vol. 24(5), pp. 73-80.

[7] Rehfeldt, R.A., Jung, H.L., Aguirre, A., et al. Beginning the Dialogue on the eTransformation: Behavior Analysis' First Massive Open Online Course (MOOC). Behavior Analysis in Practice, 2016, vol. 9(1), pp. 3-13. https://doi.org/10.1007/s40617-0150102-z

[8] Hossain, M.S., Shofiqul, I.M., Glinsky, J.V., et al. A massive open online course (MOOC) can be used to teach physiotherapy students about spinal cord injuries: a randomised trial. Journal of Physiotherapy, 2015, vol. 61(1), pp. 21-27. https://doi.org/10.1016/j.jphys. 2014.09.008

[9] Kellogg, S., Edelmann, A. Massively Open Online Course for Educators (MOOC-Ed) network dataset. British Journal of Educational Technology, 2015, vol. 46(5), pp. 977983. https://doi.org/10.1111/bjet.12312

[10] Yang, R.D., Wang, Z.F. Research on digital media education in University under mobile Internet Environment. Art Science and Technology, 2016, vol. 29(1), pp. 373-373.

[11] $\mathrm{Su}, \mathrm{B} . \mathrm{H}$. Curriculum integration of information technology and subject teaching. China Adult Education, 2006, no. 6, pp. 121-122.

[12] Zhang, M., Li, S.M., Tang, P., et al. Excellent Course Construction of Medical Information Retrieval Based on the BlackBoard Platform. Journal of Medical Intelligence, 2010, vol. 31(8), pp. 93-95.

\section{Author}

Zhuo Li is a lecturer in the University of Science and Technology Liaoning, Anshan 114051, China. (15042251746@163.com)

Article submitted 16 April 2017. Published as resubmitted by the author 22 July 2017. 